\title{
Correction to: Adsorption antagonism and synergy of arsenate(V) and cadmium(II) onto Fe-modified rice straw biochars
}

\author{
Youchi Zhang • Jiajun Fan $\cdot$ Minglai Fu $\cdot$ Yong Sik Ok $\cdot$ Yanwei Hou \\ Chao Cai
}

Published online: 27 December 2017

(C) Springer Science+Business Media B.V., part of Springer Nature 2017

\section{Correction to: Environ Geochem Health https://doi.org/10.1007/s10653-017-9984-8}

Unfortunately, in the original publication of the article, Prof. Yong Sik Ok's affiliation was incorrectly published. The author's affiliation is as follows.
1. Kangwon National University, Chuncheon 24341, Republic of Korea

2. O-Jeong Eco-Resilience Institute (OJERI), Division of Environmental Science and Ecological Engineering, Korea University, Seoul, Republic of Korea

The original article can be found online at https:// doi.org/10.1007/s10653-017-9984-8.

Y. Zhang · J. Fan · M. Fu · C. Cai (ه)

Key Lab of Urban Environment and Health, Institute of Urban Environment, Chinese Academy of Sciences, 1799 Jimei Road, Jimei District, Xiamen, Fujian 361021, China e-mail: ccai@iue.ac.cn

J. Fan · Y. Hou

College of Chemical Engineering, Huaqiao University,

Xiamen 361021, China

Y. S. Ok

Korea Biochar Research Center and School of Natural Resources and Environmental Science, Kangwon National University, Chuncheon 24341, Korea

Y. S. Ok

O-Jeong Eco-Resilience Institute (OJERI), Division of Environmental Science and Ecological Engineering, Korea University, Seoul, Republic of Korea

e-mail: yongsikok@korea.ac.kr 